\title{
Towards the Development of a New Model for Best Practice and Knowledge Construction in Virtual Campuses
}

\author{
Antonio Cartelli \\ University of Cassino, Italy \\ cartan@unicas.it \\ Thomas Connolly \\ University of the West of \\ Scotland, UK \\ thomas.connolly@uws.ac.uk
}

\author{
Mark Stansfield \\ University of the West of \\ Scotland, UK \\ mark.stansfield@uws.ac.uk
}

Athanassios Jimoyiannis

University of Peloponnese,

Greece

ajimoyia@uop.gr

\author{
Katherine Maillet \\ Institut National des \\ Telecommunications, France \\ katherine.maillet@int-evry.fr
}

\section{Executive Summary}

This paper reports on the work of a European Commission DG Education and Culture cofinanced project PBP-VC, Promoting Best Practice in Virtual Campuses, which is aimed at providing a deeper understanding of the key issues and critical success factors underlying the implementation of virtual campuses. The paper out lines a tentative model of issues underpinning best practice in virtual campuses derived from an initial literature-based investigation of existing virtual campus initiatives within the European Union. It is proposed that the tentative model will build upon key principles that have been identified for the development of an online constructivist learning environment based on problem-based learning and on a suitable model for knowledge construction and evolution.

The tentative model comprises five main areas that can be viewed as being interrelated:

Material published as part of this publication, either on-line or in print, is copyrighted by the Informing Science Institute. Permission to make digital or paper copy ofpart or all of these works for personal or classroomuse is granted without fee provided that the copies are not made or distributed for profit or commercial advantage AND that copies 1) bear this notice in full and 2) give the full citation on the first page. It is permissible to abstract these works so long as credit is given. To copy in all other cases or to republish or to post on a serveror to redistribute to lists requires specific permission and payment ofa fee. Contact Publisher@,InformingScience.org to request redistribution permission.
1. Organizational issues

2. Technological issues

3. Pedagogical Issues

4. Financial Issues

5. Consolidation Issues

At a meta level the authors hypothesize the presence of the sustainability issue. The project is working towards developing a practical framework to help guide 
the process of creating best practice in virtual campuses, as well as raising awareness of issues and approaches to creating sustainable virtual campuses.

In addition to the investigation of European Union virtual campus projects, the paper will consider virtual campus projects out side the European Union (e.g. North America, Asia, Africa) in order to identify best practices and explore the use of constructivist learning environments.

The last phase of the PBP-VC project will be to conduct in depth face-to-face research with specific virtual campus projects and initiatives in order to learn more about the issues that underpin best practice, as well as sending out detailed questionnaires to virtual campus projects and initiatives throughout the European Union, as well as beyond. The detailed framework for best practices built upon the principles for the development of an online constructivist learning environment based on problem-based learning highlighted in this paper will be at last developed and refined.

Keywords: Virtual Campuses, eLearning, Best Practice, Constructivist Learning Environments, Problem-Based Leaming

\section{Introduction}

Over the past decade, eLearning and the development of virtual campuses have evolved and developed at such a rapid rate that they are commonly accepted as an increasingly popular alternative to traditional face-to-face education (Connolly, MacArthur, Stansfield, \& McLellan, 2007; Guna wardena \& McIsaac, 2004). The demand for higher education is expanding exponentially throughout the world with the majority of Universities now offering an array of eLearning programs and modules to students from a wide range of different backgrounds and geographical locations. Many universities have entered into partnership agreements with other higher education institutions and education authorities to develop virtual universities and campuses in which students can gain access to a range of educational experiences and resources through virtual means.

The development of eLearning and virtual campus opport unities can be widely attributed to the changing nature of employment, where a job for life is no longer the norm, and to the arrival of the 'knowledge-driven society'. In this society, information and knowledge spreading and sharing have a great value due to the complexity of situations and phenomena and for the adaptability and flexibility people are asked for. Many authors hypothesized different scenarios and learning contexts for helping people in the development of the right skills and competences; among them Brown, Collins, and Duguid (1989) and Jonassen (1994) have emphasized the need for openended explorat ory authentic online learning environments in which leamers can develop meaningful and transferable knowledge and understanding.

Many eLearning developments and virtual university/campus initiatives were hindered by much of the hype and unrealistic expectations that plagued them in the mid-late 1990s. This contributed to the failure of a number of high profile eLearning and virtual campus initiat ives across the world (e.g. California Virtual University, Danish Virtual University). If eLearning and virtual campus initiatives are to be sustainable then it is vital that stakeholders understand how new models ofteaching and leaming transform the institution and how they can be used to enhance knowledge construction, flexibility, and inclusiveness. There is now an emphasis on constructivism as a philosophical, epistemological, and pedagogical approach. Constructivism focuses on knowledge construction, not knowledge reproduction. Many researchers have expressed their hope that constructivism will lead to better educational soft ware and better learning. This has led to the development of constructivist learning environments (CLEs) that guide and support leamers to achieve their intended learning outcomes (Cartelli, 2006; Connolly \& Stansfield, 2007). 


\section{The Development of eLearning and Virtual Campuses within the European Union}

Over the last five years there have been numerous eLearning and virtual campus initiatives and projects that have been co-financed by the European Commission. Despite the many successes and positive outcomes that have arisen from these projects and initiatives, a European Commission workshop held in 2005 to explore the issues associated with virtual campuses highlighted the need for a critical review of existing projects and initiatives (EACEA, 2005). The workshop highlighted a range of issues that affected the successful implementation and deployment of virtual campuses and their long term sustainability. It was felt that virtual campuses generally have very little contact and interoperability with each other due to:

- A general lack of awareness about other virtual campuses;

- A lack of self-promotion/dissemination by virtual campuses;

- Cross-cultural and linguistic barriers to communication.

Much of the relevant data, results, conclusions, and recommendations in relation to best practice gathered from numerous virtual campus projects and initiatives are scattered across numerous publications held within a wide range of individual organizations, and in many cases they are not easily accessible to the wider community. In addition, there is a vast number of websites and portals relating to individual projects with little cross-reference between them. As a result, the impact of important lessons gained from these projects and initiatives can be seriously diminished due to a lack of valorization of previous and exist ing work and the sharing and transfer of know-how in order to create a firm basis and positive environment for the development of fut ure virtual campus initiatives.

Whilst technology might be leading change at a rapid pace, it could be argued that too little attention is being paid to exploring the new forms of pedagogy made possible by eLearning and virtual campuses. It is vital that effective staff development is provided within educational institutions so that online tut ors and developers change the way they think about teaching and learning and how to employ emerging technologies to enhance learning. Virtual campuses are only as good as are the people who provide and deliver the learning experiences and support. Having the most up-todate and innovative technologies in it self will not guarantee success and learner satisfaction.

If virtual campuses are to be sustainable, this presents a number of key economic, social, pedagogical, and technological challenges that learning providers must address. Specific issues, such as ensuring that virtual campus eLearning methods provide for cost effective and sustainable learning, are vital to ensuring long term success. The issue of how eLearning can be evaluated in its costs and funded is vital for many educational institutions across the world with limited resources. There are challenges in addressing the needs of learners from diverse backgrounds whose cultural experiences might be different from the dominant educational culture which underpins their online course. This is particularly relevant within the context of the international delivery of online courses and franchising or joint partnership agreements between educational institutions in different countries and continents in the creation of virtual campuses.

It was with these issues in mind that the Promoting Best Practice in Virtual Campuses (PBP-VC) project was formed and a project proposal submitted to the 2006 European Commission Education, Audiovisual and Culture Executive Agency (EACEA) eLearning Virtual Campuses call and was subsequently selected for co-financing.

The PBP-VC project is a two year project aimed at providing: 
Towards the Development of a New Model ...

- A deeper understanding of the key issues and critical success factors underlying the implementation of virtual campuses;

- A published practical framework to help guide the process of creating best practice in virtual campuses;

- Published examples of best practice, case studies and case scenarios;

- Raised a wareness of the issues and approaches to creating successful and sustainable virtual campuses;

- Raised a wareness of how institutional transformation can be brought about by the development and application of new models ofteaching and learning for virtual campuses;

- Raised a wareness of how the successful implementation of virtual campuses contributes to the Bologna process and enhances the curricula and the quality of courses.

The PBP-VC project involves working with key stakeholders throughout the European Union in order to investigate best practice in virtual campuses. The findings from PBP-VC are aimed at helping institutions and other key stakeholders understand the issues surrounding virtual campus projects and the conditions necessary to help them progress to a strat egic level and thereby achieve inst it ut ional transformation.

The definition of a European virtual campus adopted by the PBP-VC project is the one formulated by the EACEA (2004) within the context of the eLearning program which refers to:

"cooperation between HEI (High Education Institution) in the field of eLearning regarding: design of joint curricula development by several universities, including agreements for the evaluation, validation and recognition of acquired competences subject to national procedures, large-scale experiments of virtual mobility in addition to physical mobility and development of innovative dual mode curricula, based on both traditional and on-line learning methods."

The broad definition put forward by the EACEA involved many issues from partnerships between traditional and/or distance universities and HEI in view of offering joint certificates for undergraduate and/or postgraduate levels to cooperation with learning support services. Also included in the definition are collaborative activities in strat egic education or research areas through cooperation involving a wide range of different stakeholders, such as researchers, academics, students, management, administrative, and technical personnel. The EACEA clearly state that "virtual campus' should in no way be confused with eLeaming platforms.

\section{Towards the Development of a Best Practice Framework for Virtual Campuses}

As part of the initial work carried out by the $\mathrm{PBP}-\mathrm{VC}$ project, a literature-based investigation was conducted into the 2004, 2005, and 2006 EACEA co-financed virtual campuses projects. The investigation involved looking at papers, reports, and web-based content relating to the projects. As a result, initial issues which might underpin best practice were identified and these were further developed. They are shown in Figure 1. 


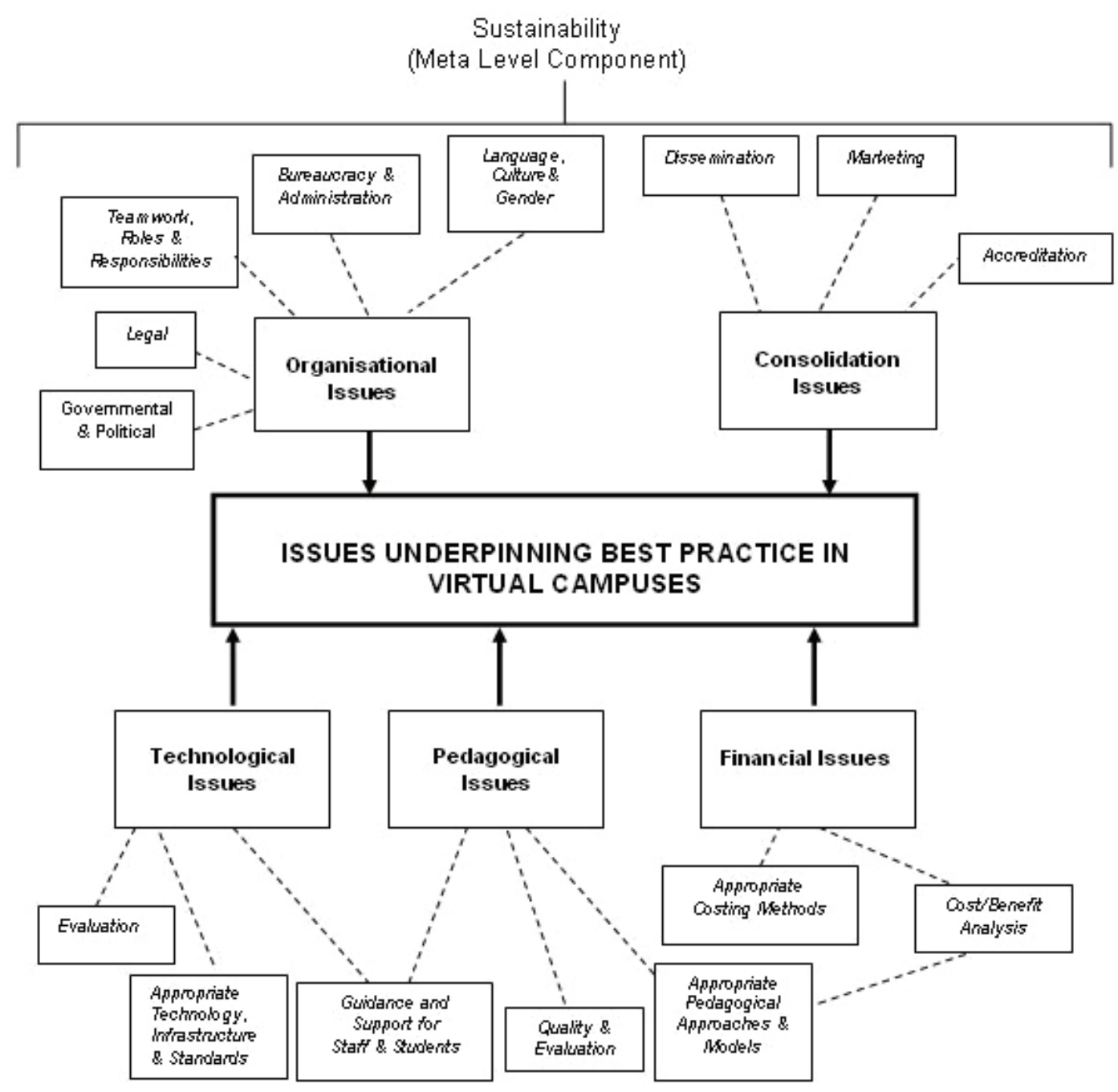

Figu re 1: A ten tative model of issues unde rpinning best practice in virtual campuses

The tentative model in Figure 1 comprises five main areas that can be viewed as being interrelated:

\section{Organizational Issues}

Initial investigation into the virtual campuses sugge sts that these appearto play an import ant role in success and underpinning best practice and in many ways can be the most difficult issues to address since they comprise largely human/'soft' elements. Such issues include bureaucracy and administration that can differ markedly among virtual campus partners and cause significant problems in attempting to provide seamless, coherent educational experiences and exit awards, particularly when a program is delivered between numerous partners across international boundaries. A number of virtual campuses highlighted this as being a difficult issue that had to be addressed early on in the development of a virtual campus. Also related to this issue is differing government, political, and legal systems, which can affect important concerns, such as copyright, in terms of publishing and the ownership of materials and courses that have been developed. The problem of language and culture was highlighted by some virtual campus projects and initiatives 
in relation to many of the programs having to be delivered in English which could be the second or third language of some of the staff and students. In addition, certain institutions and subject areas may have a cultural resistance to eLearning and the concept of virtual campuses that may lead to problems in the uptake and successful completion of programs. Also included within organizational issues are the problems relating to effective teamwork and agreeing on roles and responsibilities and ensuring that all partners work well together in achieving the outcomes of the virtual campus project. The adverse effect of this issue can be reduced in situations where the project partners have worked with each other on previous projects and initiatives in which effective teamwork has already been established within the partnership.

\section{Technological Issues}

This issue can be problematical in situations where it might be difficult for the partners to initially agree on the adoption of common platforms and software, particularly if certain inst it utions adopt different VLEs. This can also cause problems in the integration of other functions, such as student record and accounting systems. Many of the virtual campus projects and initiatives highlighted the importance of providing sufficient guidance and support to both staff and students in the use of the virtual campus platforms and technologies. Some Virtual campuses noted that it was often staff who appeared to have the greatest difficulties in learning to use new technologies. Also identified as being an important issue was the need to frequently evaluate and monitor the use of the virtual campus plat forms to ensure that staff and students were using them in the most effective way. In addition, some virtual campus projects noted that through evaluation they were able to determine which where the most popular virtual campus functions, which were not always the ones that the developers might have intended.

\section{Pedagogical Issues}

The choice of appropriate pedagogical models and approaches underpinning virtual campuses is of great importance since it has a big impact on the educational experience of the students in which problems in this area can affect student retention. Therefore, it is vital that the pedagogy underpinning a virtual campus supports and enhances the students' experience in learning a particular subject area. Providing proper guidance to students can be an important factor in underpinning success and retention, with some virtual campus projects identifying peer support among students being part of good practice. Also supporting pedagogical issue is ensuring the quality of the teaching materials developed and evaluating them on a regular basis.

\section{Financial Issues}

Whilst all the projects received significant funding from the EACEA to enable them to develop their virtual campuses and run them during the course of the funding period, issues relating to finance are important, particularly if a virtual campus project is to be encouraged to run and become sustainable beyond the EACEA funding period. To enable this to take place appropriate costing methods and effective cost/benefit analysis are vital if a virtual campus is to become self sufficient. Therefore, appropriate pedagogical approaches and models have to be adopted that attract students to enroll on virtual campus programs and also attract funding in terms of fees from students and institutions. Very little work has been conducted into determining the true costs and benefits of providing eLearning programs and running virtual campuses and whether they can be self funding and financially sustainable.

\section{Consolidation Issues}

It is important that the benefits achieved from the development and running of a virtual campus are not lost once the formal EACEA funding period has elapsed. Therefore, consolidation issues 
reflect the kind of activities that can help achieve this, such as developing adequate marketing and dissemination plans in order to continue to promote the benefits of a particular virtual campus at targeted groups of key stakeholders such as students, government bodies, and companies in order to attract continued income to allow activities and programs to cont inue running. A number of virtual campus projects and init iatives highlighted the need to gain accreditation from professional bodies relating to their particular subject area in order to attract fee paying students to their programs, as well as gain increased standing within their professional community.

Within Figure 1, sustainability is shown as a meta-level component since it appears to overarch all of the issues ratherthan being a separate issue on its own. It could be argued that for a virtual campus to exhibit best practice the concept of sustainability should run throughout all the aspects of virtual campuses (i.e. organizational, technological, pedagogical, financial, and consolidation).

The tentative model in Figure 1 is far from being complete since it merely illustrates the main issues that have been identified so far from an initial investigation into the available literature relating to EACEA virtual campus projects.

The same model, in spite of its incompleteness, shows its organizational asset. Otherwise stated, it can be used to explain "the behavior" of any Higher Education or Virtual Campus Institution as a whole, when the reported issues / features are analyzed and discussed.

To better portray the contexts for the application of the issues in Figure 1 the table below, where subjects and the whole organization are considered, can be useful.

\begin{tabular}{||l|cc||}
\hline \multicolumn{2}{|c||}{ Table 1: Contexts for the application of the issues in Figu re 1 } \\
\hline \hline \multicolumn{1}{|c|}{ Issue } & Individuals & Organization \\
\hline \hline Organizational & & $\mathrm{X}$ \\
\hline Technological & $\mathrm{X}$ & $\mathrm{X}$ \\
\hline Pedagogical & $\mathrm{X}$ & $\mathrm{X}$ \\
\hline Financial & & $\mathrm{X}$ \\
\hline Consolidation & & $\mathrm{X}$ \\
\hline
\end{tabular}

As regards the literature, where there has been a high degree of reflection into issues relating to best practice within the context of virtual campuses, it reinforces the need for promoting cooperation and exchange of strat egic experiences between all stakeholders within the area of virtual campus developments. However, the level of contribution coming from the different organizational levels highlighted above is unclear, and some questions nat urally arise:

- Are there any psycho-pedagogical strat egies better at influencing students' awareness and understanding of the studied topics and leading them to the development of better skills?

- Are there further levels for human knowledge construction and organization which have to be considered for a more detailed analysis of the best practices to be developed in Virtual Campuses? 
In what follows a first answer to these questions will be proposed and the bases for a more detailed model conveying into a practical and replicable framework for best practice in virtual campuses are developed.

\section{Towards Constructivist Virtual Campus Learning Environments}

In order to provide stimulating and challenging learning environments within the cont ext of virtual campuses, it is important that careful consideration is given to how such learning environments are designed and developed. Connolly and Stansfield (2007) identified a number of guiding principles for the development of stimulating and challenging online constructivist learning environments based on problem-based learning. It is the authors' view that such guiding principles provide an interesting and relevant basis upon which to explore issues relating to best practice in relation to virtual campus pedagogical issues. From an initial analysis of previous virtual campus projects and initiat ives, the importance of students' engagement and retention is of great importance and underpins their success.

According to Connolly and Stansfield (2007), while traditional education has been guided by the paradigm of didactic instruction whereby learners are viewed as passively receiving information, modern education is now placing emphasis on constructivism, which focuses on knowledge construction rather than knowledge reproduction. Cognitive constructivism views knowledge as an active process in which learners construct new ideas or concepts based upon their current/past knowledge. The ultimate goal of a constructivist approach is meta-cognition in which when learners encounter a problem they can reflect, not just on the structure of the problem, but on the structuring of their approaches to the problem, and thereby attempt to generate alternative, more productive strategies. The problem-based learning model encompasses these principles. This model started out in the 1960s in medical education in the USA and Canada where groups of students were presented with a problem in the form of a patient with particular symptoms (Biggs, 1999). The students' task is to diagnose the patient's condition and be able to justify the diagnosis and recommend treatment. In diagnosing the condition, the students have to discuss the symptoms, generate hypotheses based on what ever knowledge and experience they have, and ident ify learning issues. At the end of each session, the students reflect verbally on their current hypotheses and each student assumes responsibility for investigating one or more of the identified learning issues through self-directed learning.

A second authentic, constructivist approach is project-based leaming (PBL). Esch (1998) offers two continua for distinguishing between problem-based and project-based learning:

- The extent to which the end product is the organizing centre of the project. At one end of this continuum, end products are elaborate and shape the production process and, at the other end, end products are simpler and more summative, such as a group's report on their research findings. The former case typifies project-based learning, where the end product drives the planning, production, and evaluation process and the latter, where the inquiry and research is the primary focus of the learning process, typifies problem-based learning.

- The extent to which a problem is the organizing centre of the project. In this case, at one end are projects in which it is implicitly assumed that any number of problems will arise and students will require problem-solving skills to overcome them and, at the other end, are projects that begin with a clearly articulated problem and require a set of conclusions and/or solution. Again, the former example typifies project-based learning and the latter typifies problem-based learning. 
In both problem-based and project-based learning, the teacher (facilitator) is available for consultation and plays a significant role in modeling the meta-cognitive thinking associat ed with the problem-solving processes. These reflect a cognitive apprenticeship environment (Collins, Brown, \& Newman, 1990) with coaching and scaffolding (e.g. offering hints, reminders, and feedback) provided to support the learner in developing meta-cognitive skills. As these skills develop, the scaffolding is gradually removed. The intention is to force learners to assume as much of the task on their own, as soon as possible.

Connolly and Stansfield (2007) put forward a number of principles for the development of an online constructivist learning environment based on problem-based learning, shown in Table 2, that appear to provide a basis for exploring best practice in relation to pedagogical issues within virtual campuses.

The guiding principles as highlighted in Table 2 have been applied and refined by Connolly and Stansfield (2007) within the context of three fully online Masters courses in Information Systems for nearly a decade. This has led to the development of a constructivist learning environment (CLE) which goes beyond eLearning in that it provides a place where learners can work together and support each other in variety of ways utilizing information and communications technologies (ICT) and information resources that enhance problem-solving activities (Wilson, 1996). Initial investigation and analysis has found that the most successful virtual campus projects and initiatives appear to adopt many of the guiding principles for the development of an online constructivist learning environment as identified by Connolly and Stansfield (2007). The next stage of the $\mathrm{PBP}-\mathrm{VC}$ project is to develop more detailed framework for best practice in virtual campuses which will incorporate the guiding principles identified by Connolly and Stanfield.

Related to the Connolly and Stansfield's guiding principles is the extensive work conducted by Cartelli $(2002,2005,2006)$ in the field of Paleography. It has been reported that the suitable use of online web technologies contributed in creat ing constructivist learning environments, helping students in developing cognitive apprenticeship strat egies, and in improving students learning and performance. In addition, the students were better able to develop problem-solving skills not detected in more traditional teaching approaches, as well as form effective communities of learners. Cartelli (2006) also deduced that students construct knowledge in at least three different ways:

(i) Individual knowledge - autonomously interacting with phenomena, real, or virtual.

(ii) Community knowledge - being an active part of the community of learners or the community of practicethey are immersed in, where mediation and support from peers play an important role.

(iii) Social knowledge - socially interacting with other individuals in the community and with other communities. 


\begin{tabular}{|c|c|}
\hline \multicolumn{2}{|r|}{$\begin{array}{l}\text { Table 2: Guiding Principles for the Development of an Online Constructivist Learning } \\
\text { En vironment Based on Problem-Based Learning (Connolly \& Stans field, 2007) }\end{array}$} \\
\hline No. & $\begin{array}{l}\text { Guiding Principles for the Development of an Online CLE } \\
\text { Based on Problem-Based Learning }\end{array}$ \\
\hline 1. & $\begin{array}{l}\text { Allow learners to choose a (thickly) authentic project grounded in professional practice. The pro- } \\
\text { ject should be sufficiently complex to develop analytical and problem-solving skills. It should } \\
\text { also be both personally meaningful and relate to the real-world outside the classroom. }\end{array}$ \\
\hline 2. & $\begin{array}{l}\text { Encourage learners to take responsibility (ownership) for learning and to be aware of the knowl- } \\
\text { edge construction process. }\end{array}$ \\
\hline 3. & Allow learners to develop their own processes to reach a solution. \\
\hline 4. & $\begin{array}{l}\text { Provide learn ers with the opportunity to experience and appreciate other perspectives (this may } \\
\text { come about as part of the next principle). }\end{array}$ \\
\hline 5. & $\begin{array}{l}\text { Provide opportunities for interaction and collaboration (learner-learner, learner-teacher, or } \\
\text { learner-system). }\end{array}$ \\
\hline 6. & $\begin{array}{l}\text { For group-bas ed work, there must be 'group goals' and 'individual accountability' for effective } \\
\text { collaborative learning (Slavin, 1989). }\end{array}$ \\
\hline 7. & $\begin{array}{l}\text { Ensure that the learning environment motivates, engages, and challenges the learn er. The envi- } \\
\text { ronment should support the cognitive preference of the learn ers (Connolly et. al., 2007). }\end{array}$ \\
\hline 8. & Provide feedback mechanisms to enable learners to be fully aware of their progress. \\
\hline 9. & $\begin{array}{l}\text { Provide support mechanisms for learn ers using coaching and scaffolding (which should gradu- } \\
\text { ally be removed). }\end{array}$ \\
\hline 10. & Be flexible to support different learning styles. \\
\hline 11. & $\begin{array}{l}\text { Encourag e learn ers, and provide mechanisms for learners, to articulate knowl edge and thinking } \\
\text { throughout the project. }\end{array}$ \\
\hline 12. & $\begin{array}{l}\text { Encourage learners, and provide mech anisms for learners, to reflect on their activities both dur- } \\
\text { ing the project and after completion of the project. This reflection should be both group-based } \\
\text { and individual-based. }\end{array}$ \\
\hline 13. & Provide opportunities for debriefing at the end of the project. \\
\hline 14. & $\begin{array}{l}\text { Provide an integrated assessment (in our case, the instrument of assessment is the proj ect itself, } \\
\text { which can be assessed in a variety of ways). }\end{array}$ \\
\hline
\end{tabular}


This knowledge construction process is shown graphically in Figure 2 as a tri-partition of the individual's knowledge.

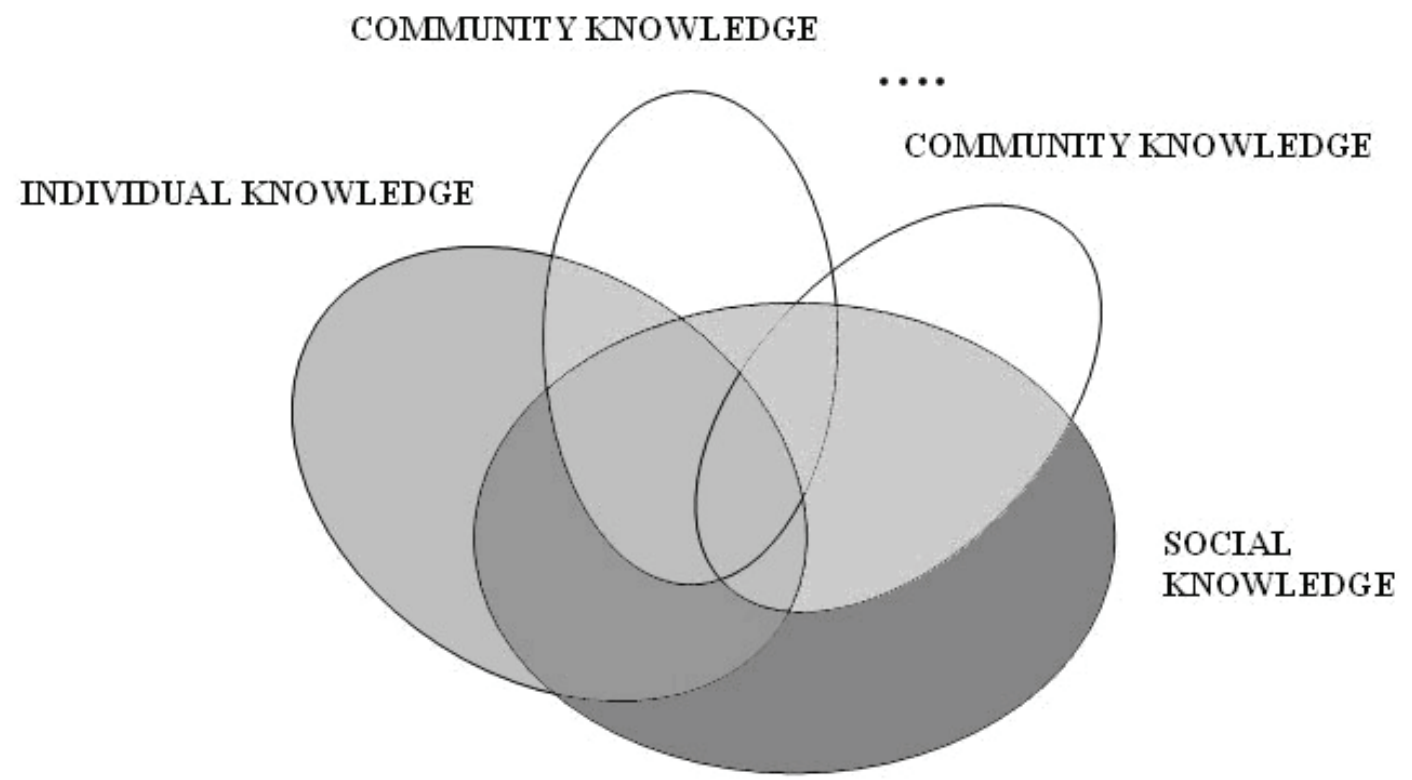

Figu re 2: The knowledge building process as a tri-partition of an individu al's knowle dge (Cartelli, 2006)

Further analyses on the above model, coming from its application to master courses for teachers, led to the hypothesis of its extensions to the explanation of construction knowledge phenomena in communities and in the whole society.

As a conclusion the above model is general enough to explain all knowledge construction phenomena and to describe the ways communication acts among the act ors of those phenomena.

Within the context of developing a framework for best practice in virtual campuses, the authors consider the guiding principles for the development of an online constructivist learning environment based on problem-based learning as developed by Connolly and Stansfield (2007) and the knowledge construction process put forward by Cartelli (2006) to be an interesting and potentially fruitful basis upon which to develop effective problem-based learning for students studying specific subjects through a virtual campus. The potential for virtual campuses to encompass Constructivist Learning Environments (CLE) provides an opportunity for engaging environments for eLearning. The next stage of the PBP-VC project is to conduct a detailed investigation into the pedagogy underpinning virtual campus projects and initiatives in order to determine the extent to which constructivist learning principles and environments have been adopted and how learning practices and approaches can be enhanced.

\section{Conclusion}

The PBP-VC project is reaching the end of its first year of the two years project and the initial literat ure based investigations have proved to be a very useful starting point in the development of a framework to promote best practice in virtual campuses. In addition to investigating European Union virtual campus project, the project will also be investigat ing virtual campus projects outside the European Union (e.g. North America, Asia, Africa) in orderto identify best practice 
and explore the use of constructivist learning environments. The next phase of the PBP-VC project is to conduct in depth face-to-face research with specific virtual campus projects and initiatives in order to learn more about the issues that underpin best practice, as well as sending out detailed questionnaires to virtual campus projects and initiatives throughout the European Union, as well as beyond. A detailed framework for best practice that builds upon the principles for the development of an online constructivist learning environment based on problem-based learning highlighted in this paper will be developed and refined. It is hoped that the work of the PBP-VC project will generate interesting and lively debate among different stakeholders (e.g. students, tutors, decision-makers, government bodies, professional bodies) which will contribute to a better understanding best practices and the role of constructivist learning environments within virtual campuses.

\section{Notes}

This work has been made possible for the European Commission Education, Audiovisual and Culture Executive Agency (EACEA) grant number 2006-4808/001 - 001 ELE ELEB12

\section{References}

Biggs, J. (1999). Teaching for quality learning at university. Buckingham: Open University Press.

Brown, J. S., Collins, A., \& Duguid, P. (1989). Situated cognition and the culture of learning. Educational Researcher, 18(1), 32-42.

Cartelli, A. (2002). Web technologies and sciences epistemologies. In Proceedings of the Informing Science and IT Education Conference, InSITE 2002 Conference, Cork, Ireland. Retrieved from http://proceedings.informingscience.org/IS2002Proceedings/papers/Carte203Webte.pdf

Cartelli, A. (2005). Computing and ICT literacy: From students' misconceptions and mental schemes to the monitoring of the teaching-learning process. In D. Carbonara (Ed.), Technology literacy applications in learning environments (pp. 37-48). Hershey, PA: Idea Group Publishing.

Cartelli, A. (2006). ICT, knowledge construction, and evolution: Subject, community and society. In A. Cartelli (Ed.), Teaching in the knowledge society: New skills and instruments for teachers (pp. 33-53). Hershey, PA: Idea Group Publishing.

Collins, A., Brown, J. S., \& Newman, S. E. (1990). Cognitive apprenticeship: Teaching the craft of reading, writing, and mathematics. In L. Resnick (Ed.), Knowing, learning, and instruction: Essays in honor of Robert Glaser. Hillsdale, NJ: Lawrence Erlbaum.

Connolly, T. M., MacArthur, E., Stansfield, M. H., \& McLellan, E. (2007). A quasi-experimental study of three online learning courses in computing. Computers \& Education, 49, 345-359.

Connolly, T. M., \& Stansfield, M. H. (2007). Developing constructivist learning environments to enhance learning. In N. Buzzetto-More (Ed.), Principles of effective online teaching: A handbook for experienced teachers developing elearning (pp. 19-38). Santa Rosa, CA: Informing Science Press.

EACEA. (2004). The 'e' in our universities - Virtual campus: Organizational changes and economic models. Report on the Consultation Workshop, $23^{\text {rd }}$ November 2004, Brussels. Retrieved from http://ec.europa.eu/education/programmes/elearning/doc/workshops/virtual\%20 campuses/report en.pd f

EACEA. (2005). Virtual campuses. Report on consultation workshops, $11^{\text {th }}$ October 2005, Brussels. Retrieved from http://ec.europa.eu/education/programmes/elearning/doc/workshops/virtual $\% 20$ campuses/report 2005 en.pdf

Esch, C. (1998). Project-based and problem-based: The same or different? Retrieved 11 September, 2005, from http://pblmm.k12.ca.us/PBLGuide/PBL\&PBL.htm 
Gunawarden a, C. N., \& McIsaac, M. S. (2004). Distance education. In D. H. Jonassen (Ed.), Handbook of research for educational communications and technology (2nd ed.) (pp. 355-396). Mahwah, NJ: LEA.

Jonassen, D. H. (1994). Thinking technology: Toward a constructivist design model. Educational Technology, 34(3), 34-37.

Slavin, R. E. (1989). Research on cooperative learning: An international perspective. Scandinavian Journal of Educational Research, 33(4), 231-243.

Wilson, B. (1996). Constructivist learning environments: Case studies in instructional design. Englewood Cliffs, NJ: Educational Technology Publications.

\section{Biographies}

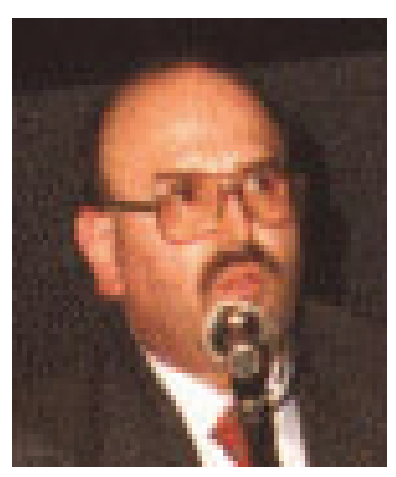

An tonio Cartelli is a researcher in Didactics and special pedagogy. He manages the Laboratory for Teaching-Learning T echnologies and the Centre for ICT and on line teaching in the Faculty of Humanities at the University of Cassino - Italy. Among his interests are: misconceptions, mental schemes, Information Systems for research and teaching, Web T echnologies in teaching research and their everyday application for the improvement of teaching and learning. He is also author of many papers and books concerning the themes he is interested in.

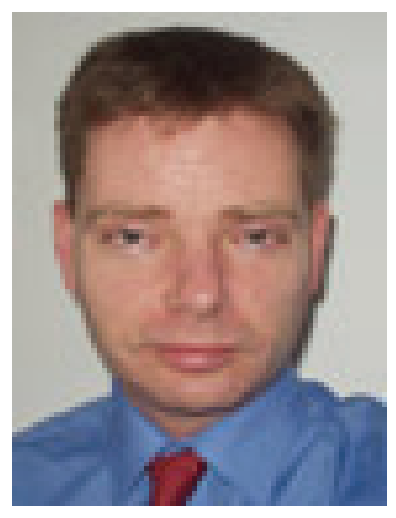

Mark Stansfield is a Senior Lecturer in the School of Computing at the University of the West of Scotland. He has aPhD in Information Systems and has published papers on eLearning, games-based eLearning and information systems in a number of international journals.

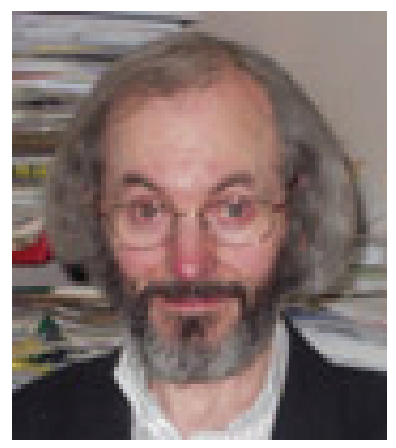

Thomas Connolly is a Professor in the School of Computing at the University of the West of Scotland. He has worked for over 15 years in industry as a Manager and Technical Director in international soft ware houses before entering academia. He is a specialist in eLearning, games-based eLearning and database systems. 

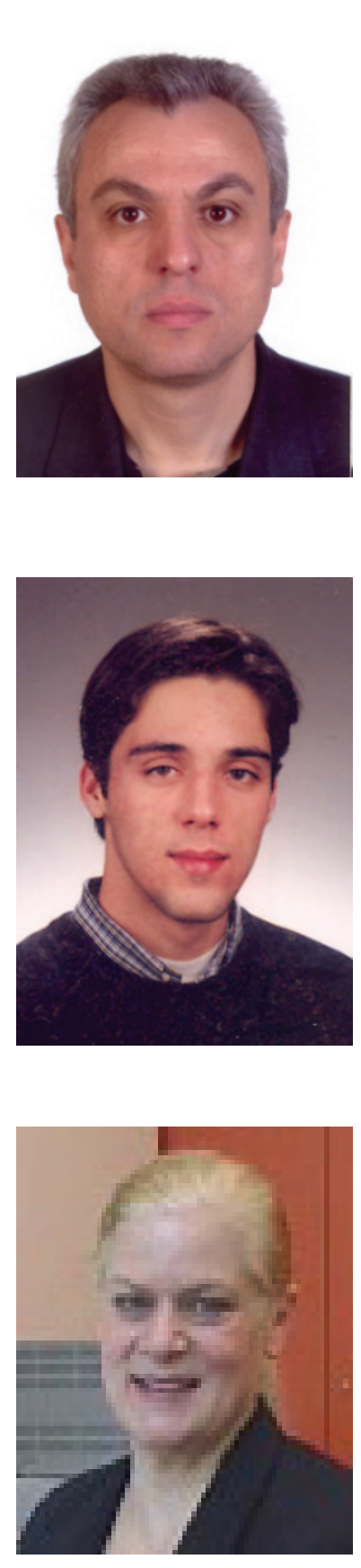

Athan assios Jimoyian nis is an assistant professor of Science and ICT in Education at the University of Peloponnese in Greece since 2005. He has received his $\mathrm{PhD}$ from the University of Ioannina in 1991.Prior to his current position he has been assistant professor at the Department of Preschool Education, University of the Aegean, and instructor at the Technical and Vocational Teacher Training Inst it ute in Greece. His current research interests include e-learning and ICT in education, teachers' preparation about ICT in education, computer science education and science education. He is one of the co-editors of the international journal THEMES in Science and Technology Education. He is a reviewer in various international journals and conferences in the areas of e-leaming and ICT in education.

Hugo Magalhães is consultant at SPI since October 2006, where he has worked on projects in the areas of knowledge management, innovation, research and development. He has a diploma in Applied Mathematics to Technology and a PhD in Applied Mathematics from the Sciences Faculty of the University of Porto, Portugal. He is author and co-author of more than twenty scientific articles in conferences and international journals and co-author of a book entitled "Segurança Informática e o Negócio Electrónico", belonging to the collection Negócio Electrónico, published by SPI.

Kathe rine Maillet has twenty-five years of professional experience in teaching and research: authoring distance learning courses, "virtual student mobility", curriculum design, administration, project management, consulting, publishing research results. She was head of the foreign language department at INT for 10 years during which she was responsible for designing, implementing, and directing the foreign language curriculum, learning facilities, and its associated educational and administrative operations. She has been involved in a number of national and international projects which aimed to integrate advanced communications technologies into language teaching and learning methodologies. 